\title{
Inhibitory Effect of the Ethanol Extract of a Rice Bran Mixture Comprising Angelica gigas, Cnidium officinale, Artemisia princeps, and Camellia sinensis on Brucella abortus Uptake by Professional and Nonprofessional Phagocytes
}

\author{
Huynh Tan Hop ${ }^{1}$, Lauren Togonon Arayan ${ }^{1}$, Alisha Wehdnesday Bernardo Reyes ${ }^{1}$, Tran Xuan Ngoc Huy ${ }^{1}$, \\ Eun Jin Baek ${ }^{1}$, WonGi Min ${ }^{1}$, Hu Jang Lee ${ }^{1}$, Chun Hee Lee ${ }^{2}$, Man Hee Rhee ${ }^{2}$, and Suk Kim ${ }^{1 *}$ \\ ${ }^{1}$ Institute of Animal Medicine, College of Veterinary Medicine, Gyeongsang National University, Jinju 52828, Republic of Korea \\ ${ }^{2}$ College of Veterinary Medicine, Kyungpook National University, Daegu 41566, Republic of Korea
}

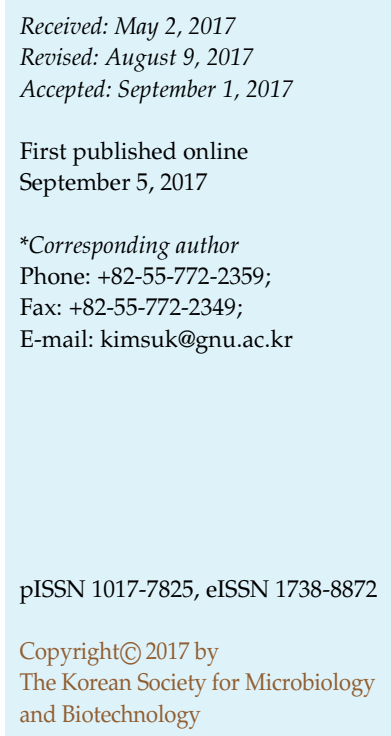

In this study, we evaluated the inhibitory effect of a rice bran mixture extract (RBE) on Brucella abortus pathogenesis in professional (RAW 264.7) and nonprofessional (HeLa) phagocytes. We fermented the rice bran mixture and then extracted it with $50 \%$ ethanol followed by gas chromatography-mass spectrometry to identify the components in RBE. Our results clearly showed that RBE caused a significant reduction in the adherence of B. abortus in both cell lines. Furthermore, analysis of phagocytic signaling proteins by western blot assay revealed that RBE pretreatment resulted in inhibition of phosphorylation of JNK, ERK, and p38, leading to decline of internalization compared with the controls. Additionally, the intensity of F-actin observed by fluorescence microscopy and FACS was remarkably reduced in RBE-pretreated cells compared with control cells. However, the intracellular replication of B. abortus within phagocytes was not affected by RBE. Taken together, these findings suggest that the phagocytic receptor blocking and suppressive effects of RBE on the MAPK-linked phagocytic signaling pathway could negatively affect the invasion of B. abortus into phagocytes.

Keywords: B. abortus, phagocyte, rice bran mixture extract, phagocytic signaling, pathogenesis

\section{Introduction}

Brucella spp. are facultative intracellular gram-negative bacteria that cause brucellosis in animals and humans. They can invade and replicate within a variety of phagocytes, such as macrophages, epithelial cells, and placental trophoblasts, displaying diverse interactions with host cells. However, the underlying mechanisms of host invasion are not fully understood [1, 2]. Brucella spp. have developed stealthy survival strategies, and thus there exists a need to develop new therapeutic interventions [3].

Vaccination seems to be the predominant strategy to eliminate this disease; however, there is no $100 \%$ efficacious vaccine for animals and humans. The current live-attenuated Brucella strains such as B. abortus S19 or B. melitensis Rev 1 strain used for cattle and goat still have some disadvantages, including abortion in animals when administered during pregnancy and being fully virulent for humans [4]. Additionally, elevated doses and extended use of antibiotics are still under debate [1]. Biological therapy should therefore be a major consideration due to the disadvantages and financial burden of conventional therapy in the treatment of infectious diseases [5].

Rice bran mixture extract (RBE) is mainly extracted from four traditional medicinal plants in Asia; namely, Angelica gigas, Cnidium officinale, Artemisia princeps, and Camellia sinensis. These have been reported as efficacious against bacterial infection, inflammation, and cancer. In particular, various pharmacological properties of Angelica gigas have been reported recently, such as antibacterial $[6,7]$, anticancer 
[8, 9], antitumor [10], antioxidant, and neuroprotective activities [11]. In parallel, the ethanol extract from Cnidium officinale was shown to affect the release of proinflammatory mediators, TNF- $\alpha$, IL-1 $\beta$, IL- 6 , and nitric oxide (NO), in murine peritoneal macrophages and splenocytes [12]. In addition, Artemisia princeps is widely used to maintain hemostasis and in the treatment of pain, inflammation, amenorrhea, uterine hemorrhage, hemorrhoids, and menopausal diseases. Its ethanol extract inhibits the proliferation, acid production, biofilm formation, and expression of virulence genes in antibiotic-resistant bacteria [13]. On the other hand, green tea, produced from the leaves of the plant Camellia sinensis, is one of the most popular beverages consumed worldwide and is a rich source of dietary flavonoids in humans. Recently, the antimicrobial activity of Camellia sinensis extract was demonstrated against multidrug-resistant bacteria [14].

Although various activities of the individual extracts on bacterial infections involved in host immune response have been evaluated, their effects on the infection with B. abortus have not been elucidated. Thus, in this study, we investigated the specific effects of RBE on B. abortus infection.

\section{Materials and Methods}

\section{Bacterial Strain and Cell Culture}

A smooth, virulent B. abortus 544 biovar 1 strain was cultured in Brucella broth (BD Biosciences, USA) at $37^{\circ} \mathrm{C}$ until stationary phase. RAW 264.7 and HeLa cells were grown in RPMI 1640 and DMEM, respectively, at $37^{\circ} \mathrm{C}$ in $5 \% \mathrm{CO}_{2}$ atmosphere containing $10 \%$ heat-inactivated FBS with or without $100 \mathrm{U} / \mathrm{ml}$ penicillin and $100 \mu \mathrm{g} / \mathrm{ml}$ streptomycin.

\section{RBE Preparation}

The fermented RBE was prepared as follows: the rice bran containing Angelica gigas, Cnidium officinale, Artemisia princeps, and Camellia sinensis (ratio of 80:8:6:6 (v/v)) was injected with enzymes of Lactobacillus rhamnosus ( $\alpha$-D-glucosidase, $\beta$-D-glucosidase, $\alpha$-Dgalactosidase, $\beta$-D-galactosidase, $\beta$-D-glucuronidase, and in major quantity $\alpha$-L-rhamnosidase, since it is responsible for the hydrolysis of terminal non-reducing $\alpha$-L-rhamnose sugar to reducable $\alpha$-Lrhamnoside sugars, making it an important enzyme for the breakdown of sugars present in the rice bran for more bioavaibility [15]; $6.2 \times 10^{5}$ colony forming unit (CFU)/ml) and Pichia deserticola (phospholipase A1, phospholipase A2, phospholipase C, phospholipase $\mathrm{B}$, phospholipase D, and acyltransferase. Phospholipases were the major enzymes injected in rice bran mixture because they hydrolyze the breakdown of fatty acids and lecithin into bioavailable lipophilic substances forming lysolecithin that is responsible for recruitment of phagocytes; $3.7 \times 10^{4} \mathrm{CFU} / \mathrm{ml}$ ) [16]. The hydrated enzymes of Lactobacillus rhamnosus and Pichia deserticola and rice bran mixture were mixed well and then fermented at room temperature in a dark container [17]. The mixture was then extracted with $50 \%$ ethanol, filtered with Whatmann filter paper, and evaporated. Later it was freeze dried and the powdered form obtained was fermented RBE.

\section{Gas Chromatography-Mass Spectrometry Analysis}

Gas chromatography-mass spectrometry (GC-MS) was carried out as described previously [18]. Briefly, to identify its phytochemical constituents, small amounts of extracts $(2.5 \mathrm{mg})$ were analyzed by GC-MS using an Agilent Technology 7890A-Gas Chromatograph system (Agilent Technologies, USA), coupled to XLMSD-5975C equipment operating in electrospray ionization mode. The relative percentage of each component was calculated by comparing its average peak area to the total area.

\section{Bactericidal Assay}

Bacteria were diluted with PBS to a concentration of $2 \times 10^{4}$ $\mathrm{CFU} / \mathrm{ml}$, added to PBS containing different concentrations of RBE $(1,10$, and $100 \mu \mathrm{g} / \mathrm{ml})$, and incubated at $37^{\circ} \mathrm{C}$ for $0,4,8$, and $24 \mathrm{~h}$ as previously described [3]. Each diluent was then plated on Brucella agar and incubated for 3 days at $37^{\circ} \mathrm{C}$. The bacterial survival rates were expressed as the percentage of the survival rate of the treated sample relative to an untreated control, which was set at $100 \%$.

\section{Cytotoxicity Assay}

Following overnight culture in 96-well plates at $2 \times 10^{4}$ cell $/$ well, cells were treated with different concentrations of $\operatorname{RBE}(0.001,0.1,1$, and $10 \mathrm{mg} / \mathrm{ml})$ for $48 \mathrm{~h}$ at $37^{\circ} \mathrm{C}$ in $5 \% \mathrm{CO}_{2}$. The cytotoxic effect of RBE was assessed by a 3-(4,5-dimethylthiazol-2yl)-2,5-diphenyl$2 \mathrm{H}$-tetrazolium bromide (MTT) assay as previously described [3].

\section{Bacterial Uptake and Intracellular Replication Assay}

These assays were performed as previously described [3]. To analyze bacterial internalization efficiency, cells were pretreated with different non-cytotoxic concentrations of RBE $4 \mathrm{~h}$ prior to infection. Following centrifugation at $150 \times g$ for $10 \mathrm{~min}$, bacteria were infected at multiplicities of infection of 100 and incubated at $37^{\circ} \mathrm{C}$ in $5 \% \mathrm{CO}_{2}$ for 0,15 , and $30 \mathrm{~min}$. At the indicated time point, the cells were washed once with PBS and then incubated at $37^{\circ} \mathrm{C}$ in RPMI or DMEM containing 10\% (v/v) FBS and gentamicin $(30 \mu \mathrm{g} / \mathrm{ml})$ for $30 \mathrm{~min}$ to kill any remaining extracellular bacteria. The cells were washed three times with PBS, lysed with distilled water and plated on Brucella agar. Gentamicin protected percentage was calculated as the mean internalized bacteria divided by the originally infected bacteria. For the intracellular growth efficiency measurements, the infected cells were incubated at $37^{\circ} \mathrm{C}$ for $1 \mathrm{~h}$, washed once with PBS, incubated on RPMI or DMEM containing $10 \%(\mathrm{v} / \mathrm{v})$ FBS and gentamicin $(30 \mu \mathrm{g} / \mathrm{ml})$ with different noncytotoxic concentrations of RBE, and then incubated for 2, 24, or $48 \mathrm{~h}$. Cell washing, lysis, and plating procedures were the same as those utilized in the internalization assay. 


\section{Bacterial Adherence Assay}

The bacterial adherence assay was performed as previously described [2]. Briefly, phagocytes were cultured in 12-well plates with 18-mm diameter glass coverslips (Fisher Scientific, USA), at a concentration of $1 \times 10^{5}$ cells per well overnight before infection. Cells were pre-incubated with RBE $(0.1$ and $1 \mathrm{mg} / \mathrm{ml})$ for $4 \mathrm{~h}$, and during the last $40 \mathrm{~min}$ of pre-incubation, $2.5 \mu \mathrm{l}$ of cytochalasin $\mathrm{D}$ $(500 \mu \mathrm{g} / \mathrm{ml})$ was added. Cells were then infected with B. abortus and centrifuged at $150 \times g$ for $10 \mathrm{~min}$ at RT and incubated at $37^{\circ} \mathrm{C}$ in $5 \% \mathrm{CO}_{2}$ for $30 \mathrm{~min}$. The cells were washed three times with PBS, fixed with $4 \%$ paraformaldehyde, and incubated at $37^{\circ} \mathrm{C}$ for $30 \mathrm{~min}$. The adherent bacteria on the cell surface within $30 \mathrm{~min}$ of infection were monitored and the cells were washed three times with PBS and then permeabilized at $-20^{\circ} \mathrm{C}$ in methanol for $10 \mathrm{sec}$. The adherent bacteria were then stained with anti-B. abortus polyclonal rabbit serum (1:500) in PBS for $1 \mathrm{~h}$ at $37^{\circ} \mathrm{C}$ and then stained with fluorescein isothiocyanate (FITC)-conjugated goat anti-rabbit immunoglobulin G (IgG) (1:500; Sigma-Aldrich, USA) in PBS for $1 \mathrm{~h}$ at $37^{\circ} \mathrm{C}$. The preparations were washed and then mounted in DakoCytomation fluorescent mounting medium (Dako North America, Inc., USA). Fluorescence images were collected using a microscope (IX70; Olympus; Japan). One hundred macrophages were randomly selected and the bacteria that adhered to the cells were counted.

\section{Immunoblot Analysis}

The lysates of cells were identified by western blot analysis as previously described [19]. After electrophoresis, the separated proteins were transferred onto Immobilon-P membranes (Milipore, USA) in transfer buffer (25 mM Tris, $190 \mathrm{mM}$ glycine, and 20\% methanol, $\mathrm{pH}$ 8.3) for $60 \mathrm{~min}$ using a semi-dry electroblot assembly (Bio-Rad, USA). The membranes were blocked with 5\% skim milk (Difco, USA) for $30 \mathrm{~min}$ at room temperature and subsequently washed three times with phosphate-buffered saline containing $0.05 \%$ Tween-20 (PBS-T), and then incubated with primary antibodies (1:1,000 dilution) in blocking buffer at $4{ }^{\circ} \mathrm{C}$ overnight. The membranes were washed with $0.05 \%$ PBS-T and incubated with horseradish peroxidase-conjugated goat anti-mouse IgG antibody (1:5,000 dilution; Sigma) in blocking buffer for $1 \mathrm{~h}$ at room temperature and finally washed with $0.05 \%$ PBS-T. The proteins were detected with ECL solution (Thermo Scientific, USA).

\section{F-Actin Staining}

RAW 264.7 or HeLa cells were stained for F-actin and examined by immunofluorescence microscopy as previously described [2]. Briefly, 2-day cultured bacteria were harvested and stained for $20 \mathrm{~min}$ at room temperature with $1 \mathrm{ml}$ of FITC $(0.5 \mathrm{mg} / \mathrm{ml})$ in $50 \mathrm{mM}$ sodium carbonate- $100 \mathrm{mM}$ sodium chloride at $\mathrm{pH}$ 9.0. The cells were infected with FITC-conjugated bacteria for $15 \mathrm{~min}$ and then fixed with $4 \%$ paraformaldehyde for $1 \mathrm{~h}$ at $37^{\circ} \mathrm{C}$. The cells were then permeabilized with $0.1 \%$ Triton $\mathrm{X}-100$ for $10 \mathrm{~min}$ at $22^{\circ} \mathrm{C}$ and incubated with blocking buffer ( $2 \%$ goat serum in PBS) for $30 \mathrm{~min}$. The cells were incubated with $0.1 \mu \mathrm{M}$ rhodamine- phalloidin for $30 \mathrm{~min}$ and washed three times with PBS. F-actin organization was observed by fluorescence microscopy.

\section{FACS Assay}

The relative content of F-actin in B. abortus-infected and uninfected cells with or without pretreatment of RBE $(1 \mathrm{mg} / \mathrm{ml})$ was evaluated as previously described [2]. Briefly, RAW 264.7 or HeLa cells were cultured in 6-well plates and pretreated with RBE for $4 \mathrm{~h}$ prior to infection. The cells were infected for $15 \mathrm{~min}$ and fixed with paraformaldehyde at $22^{\circ} \mathrm{C}$ for $30 \mathrm{~min}$, permeabilized, and stained with $20 \mu \mathrm{g} / \mathrm{ml}$ lysophosphatidylcholine containing $1 \mu \mathrm{M}$ tetramethyl rhodamine isothiocyanate-phalloidin for $1 \mathrm{~h}$ at $22^{\circ} \mathrm{C}$. The cells were centrifuged at $300 \times g$ for $5 \mathrm{~min}$ at $4^{\circ} \mathrm{C}$ and washed three times with PBS. The F-actin content was quantified by FACS analysis using a FACS Calibur flow cytometer (BD Biosciences) and is represented on log-scale histograms depicting 10,000 cells. The average F-actin content of a population was expressed as the mean fluorescence intensity.

\section{Statistical Analysis}

The data are expressed as the mean \pm standard deviation (SD). Student's $t$-test was used to statistically compare the groups. The results with $p<0.05$ were considered statistically significant.

\section{Results}

\section{Chemical Composition Analysis of RBE}

Following the extraction of fermented rice bran mixture with $50 \%$ ethanol, GC mass spectrometry was performed to identify the chemical composition of RBE. As shown in Table 1, fatty acids and their derivatives are the primary components of RBE.

Table 1. Chemical composition of the rice bran mixture extract analyzed by gas chromatography-mass spectrometry.

\begin{tabular}{lc}
\hline \multicolumn{1}{c}{ Components } & $\%$ \\
\hline 1,4-Dihydrophenanthrene & 0.25 \\
3-Methylenecyclohexyl methyl ether & 0.19 \\
Caffeine & 0.65 \\
Benzoic acid, 3,5-dihydroxy & 0.36 \\
9-Hydroxybytyl-3,9-diazabicyclo & 0.53 \\
L-Proline & 0.69 \\
Hexadecanoic acid & 13.21 \\
9,12-Octadecadienoic acid & 37.07 \\
6-Octadecenoic acid & 39.87 \\
Linoleic acid, ethyl ester & 1.62 \\
10-Octadecenoic acid, methyl ester & 0.36 \\
Pyrrolo[1,2-a]pyrazine-1,4-dione & 0.27 \\
(2,4-Dichloro-6-nitrophenoxy) acetic acid & 0.14 \\
But-2-enoic acid & 0.47 \\
\hline
\end{tabular}




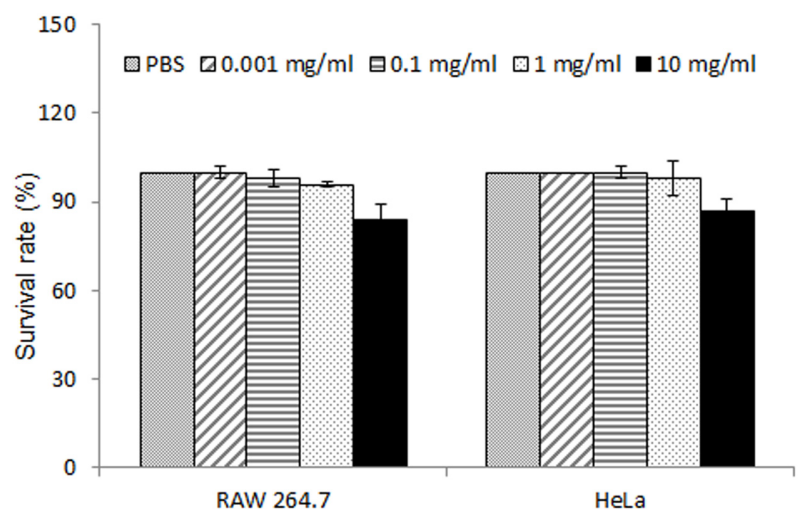

Fig. 1. Cytotoxic effect of the rice bran mixture extract on phagocytes, assessed by MTT assay.

Data are presented as the mean \pm SD of triplicates.

\section{Bactericidal and Cytotoxicity Assays}

The bacterial survival rate of RBE-treated B. abortus was not significantly different when compared with that of the controls (data not shown), suggesting that RBE has no bactericidal effect. Additionally, as shown in Fig. 1, treatment and incubation of RAW and HeLa cells with different concentrations of $\operatorname{RBE}(0.001,0.1,1$ or $10 \mathrm{mg} / \mathrm{ml})$ revealed that cell survival at a concentration of $1 \mathrm{mg} / \mathrm{ml}$ was not decreased compared with untreated cells. These results indicated that RBE did not cause any cytotoxicity to RAW and HeLa cells at or below $1 \mathrm{mg} / \mathrm{ml}$. Thus, concentrations of 0.1 and $1 \mathrm{mg} / \mathrm{ml}$ were used for subsequent experiments.

\section{Inhibitory Effect of RBE on Internalization but Not on} Intracellular Growth of B. abortus

To verify the effects of RBE on the invasion of B. abortus in RAW 264.7 and HeLa cells, phagocytes were pretreated with different concentrations of $\operatorname{RBE}(0,0.001,0.1$, and $1 \mathrm{mg} / \mathrm{ml}$ ) and then infected with $B$. abortus for the indicated times $(0,15$, or $30 \mathrm{~min})$. The results indicated that pretreatment of RBE at concentrations of 0.1 and $1 \mathrm{mg} / \mathrm{ml}$ caused a significant reduction in $B$. abortus invasion of phagocytes in a concentration-dependent manner compared with that of untreated cells (Fig. 2). However, RBE did not cause any effect on the intracellular growth of B. abortus in either of the cell lines (data not shown).

\section{Effect of RBE on B. abortus Phagocytosis Via Modulation of Adherence and F-Actin Polymerization}

Adherence is a critical step of Brucella invasion; thus, we tested whether RBE has effect on the adherence of B. abortus to phagocyte surface membranes. As shown in Fig. 3, pretreatment with 0.1 and $1 \mathrm{mg} / \mathrm{ml}$ of RBE caused significant
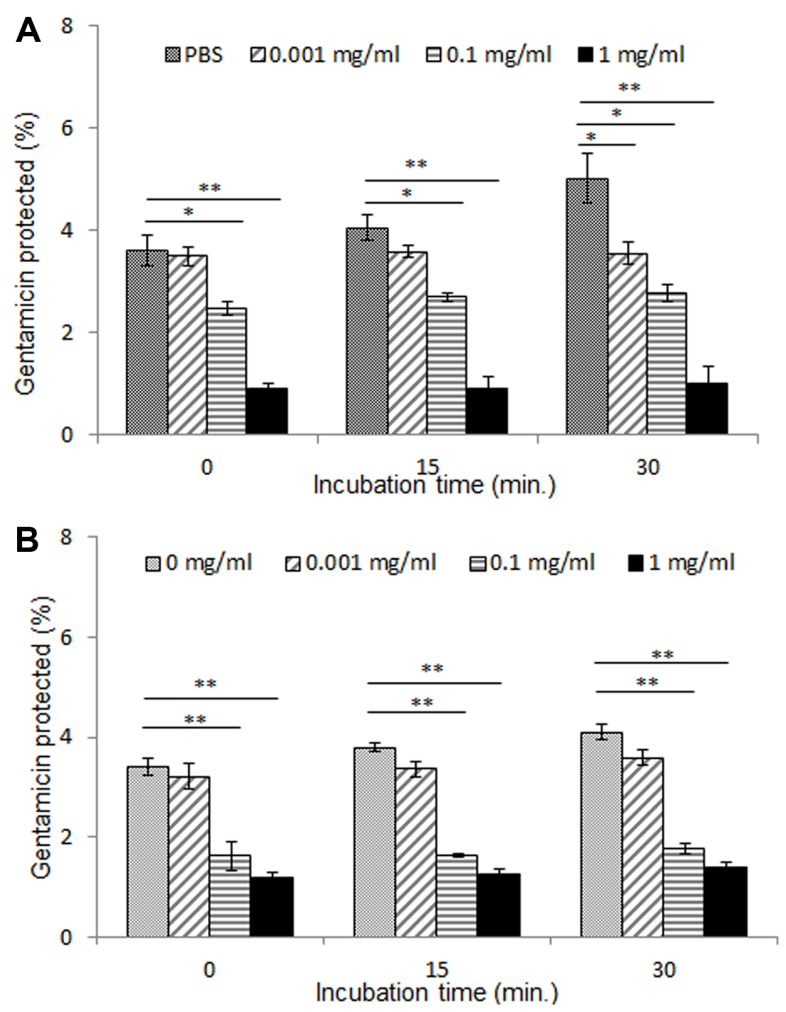

Fig. 2. Effect of the rice bran mixture extract (RBE) on B. abortus invasion.

RAW 264.7 (A) and HeLa (B) cells were pretreated with or without RBE at different concentrations and then infected with B. abortus. Log CFUs were determined at the indicated times. Data are presented as the mean $\pm \mathrm{SD}$ of triplicates. Asterisks indicate a significant difference $(p<0.05)$.

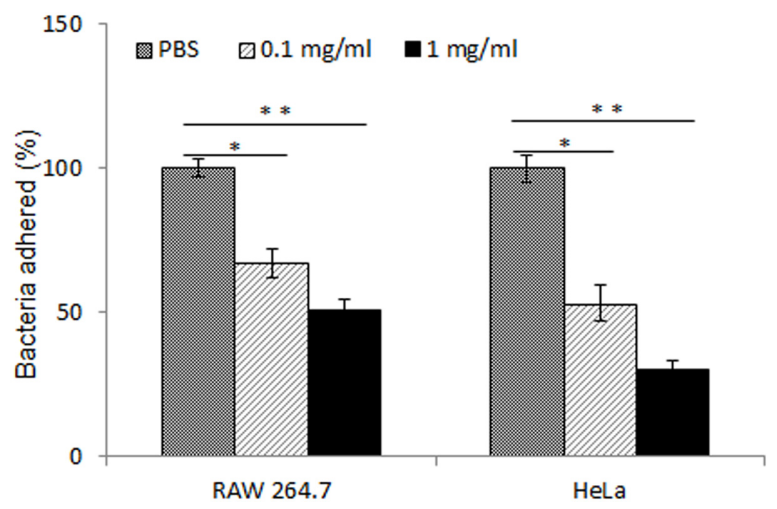

Fig. 3. Effect of the rice bran mixture extract (RBE) on bacterial adherence.

Phagocytes were pre-incubated with or without RBE and infected with B. abortus for $15 \mathrm{~min}$. The infected cells were stained with different antibodies and 100 macrophages were randomly selected and the bacteria that adhered to the cells were counted. Data are presented as the mean $\pm \mathrm{SD}$ of triplicates. Asterisks indicate a significant difference $(p<0.05)$. 
reductions of bacterial adherence of approximately $35.2 \%$ and $48.6 \%$, respectively, in RAW 264.7 cells, whereas reductions of $47 \%$ and $63.5 \%$, respectively, were observed in HeLa cells. In addition, observation by fluorescence microscopy revealed that F-actin polymerization in B. abortus invasion was attenuated in the RBE-treated cells compared with untreated control cells (Fig. 4A). In order to quantitatively evaluate the effect of RBE on the F-actin content during B. abortus invasion, FACS analysis was performed for phagocytes with or without pretreatment of RBE. Interestingly,

A
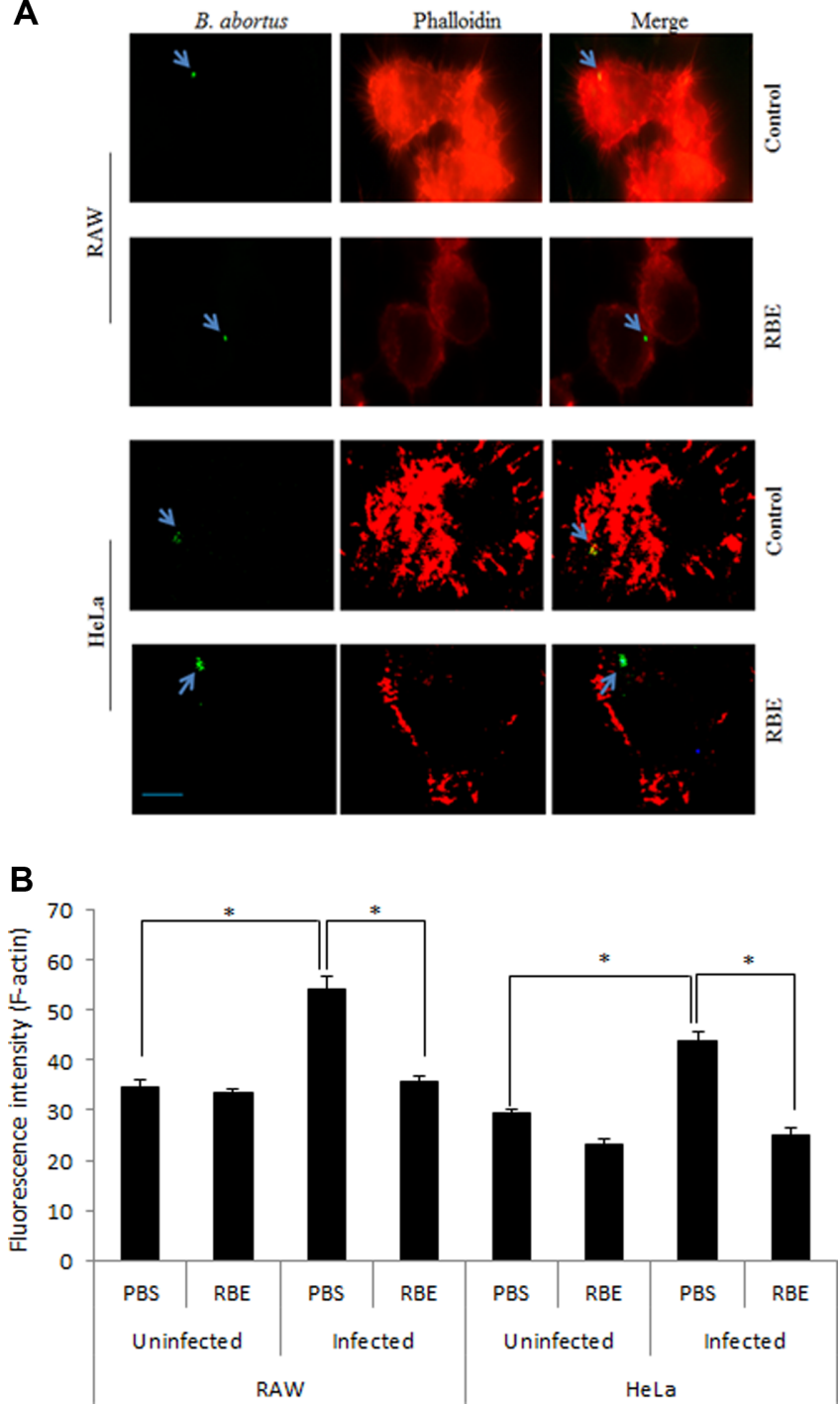

Fig. 4. Effect of the rice bran mixture extract (RBE) on Brucella phagocytosis by the modulation of F-actin polymerization. F-actin polymerization and bacterial co-localization (A) and FACS analysis for F-actin content (B) were determined. Data are presented as the mean $\pm \mathrm{SD}$ of triplicates. Asterisks indicate a significant difference $(p<0.05)$. Scale bar $=5 \mathrm{~mm}$.
RBE pretreatment led to a remarkable decrease in F-actin fluorescence intensity compared with the B. abortus-infected control cells, whereas no difference in F-actin fluorescence was found between the uninfected control cells and the RBE-treated uninfected cells for both cell lines (Fig. 4B).

\section{Downregulation of Phagocytic Signaling by RBE}

The phosphorylation levels of ERK1/2, p38a, and JNK in the RBE-treated phagocytes at $15 \mathrm{~min}$ post-infection were reduced by approximately $35 \%, 52 \%$, and $24 \%$, respectively, in RAW 264.7 cells (Fig. 5A) and reduced by 62\%, 8\%, and $37 \%$, respectively, in HeLa cells (Fig. 5B) compared with those in the infected control cells. These findings indicate that RBE could negatively regulate the activation of mitogen-activated protein kinase (MAPK), resulting in the inhibition of $B$. abortus invasion into professional and nonprofessional phagocytes.
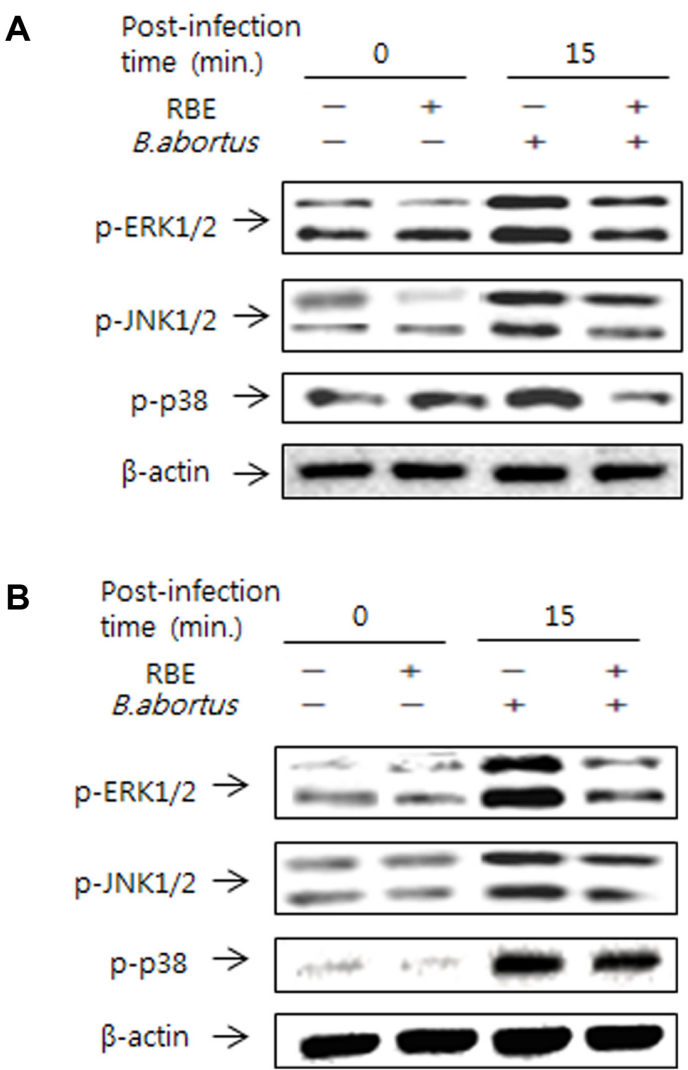

Fig. 5. Effect of the rice bran mixture extract (RBE) on activation of the signaling of phagocytes during B. abortus infection. Immunoblot analysis of total cell lysates was evaluated using phosphospecific antibodies against ERK1/2, JNK, and p38a in infected or uninfected RAW 264.7 (A) and HeLa (B) cells pretreated with or without RBE. 


\section{Discussion}

Brucella spp. are causative agents of human and animal brucellosis [1]. The prolonged use of conventional antibiotics is required for the treatment of this disease; however, this is still a controversial issue. Thus, the application of traditional medicine and natural products for the control of brucellosis seems to be a valid alternative for brucellosis treatment. The elucidation of the precise mechanisms with respect to how a natural product modulates Brucella infection is required [2].

Although the individual extracts from RBE, namely, Angelica gigas, Cnidium officinale, Artemisia princeps, and Camellia sinensis, have been reported to have a variety of pharmacological effects, such as antibacterial, anticancer, antitumor, antioxidant effects [8-13], the potential therapeutic effects of RBE on B. abortus infections have yet to be clinically examined. This study elucidated the specific effect of RBE on B. abortus infection in professional phagocytes (RAW 264.7) and nonprofessional phagocytes (HeLa).

First, we hypothesized that RBE can directly kill B. abortus. Hence, we treated free-living Brucella with RBE at different concentrations. However, our results revealed that RBE has no bactericidal activity on $B$. abortus. We then assessed its potential on internalization and intracellular growth of Brucella. Intriguingly, the bacterial uptake in RBE-treated cells was significantly diminished compared with the controls (Fig. 2); however, RBE treatment did not alter intracellular growth of B. abortus within phagocytes. Thus, we focused on elucidating the mechanism by which RBE could inhibit Brucella uptake by phagocytes.

The invasion of Brucella into host cells is likely the most crucial event in bacterial infections and depends on specific cell-to-bacteria interactions, which are directly mediated by a specific cell surface adhesion mechanism [2]. Therefore, we performed adherence assays to examine the effect of RBE on bacterial adhesion to their target cells. Our results showed that RBE pretreatment caused significant reduction of bacterial adherence to RAW 264.7 and HeLa cells, indicating that RBE interferes with Brucella-host surface interaction, which is an important step for subsequent phagocytosis. On the other hand, we also found that RBE hindered F-actin polymerization, which has been reported to be an essential event for phagocytic uptake of microbial pathogens in both epithelial cells and macrophages [2, 20,21].

Several studies have demonstrated that MAPK plays an important role in the phagocytosis of bacteria and remodeling of the actin cytoskeleton $[22,23]$. In this study, we proposed that the inhibitory effects of $\mathrm{RBE}$ on the
B. abortus invasion and F-actin polymerization resulted from the attenuation of MAPK (ERK1/2, p38a, and JNK) activation. To test this hypothesis, we evaluated the phosphorylation of MAPKs in phagocytes in the presence or absence of RBE during B. abortus invasion. As expected, the results revealed that $\mathrm{RBE}$ attenuated the activation of MAPKs (ERK1/2, p38, and JNK in RAW 264.7, whereas only ERK1/2 and JNK in HeLa) at 15 min post-infection. Taken together, these findings suggest that the suppressive effects of RBE on the MAPK-linked phagocytic signaling pathway could negatively affect the invasion of B. abortus into both professional and nonprofessional phagocytes.

Furthermore, the chemical composition of RBE analyzed by GC-MS revealed that RBE is mainly composed of shortchain fatty acids (SCFAs), suggesting the important role of SCFA-stimulated signaling during Brucella invasion. These findings paralleled previous observations that demonstrated that SCFAs inhibit Salmonella invasion through nutritional, regulatory, and immune-modulatory effects on the host physiology [24, 25].

In summary, our findings reveal that treatment of RBE could remarkably inhibit the invasion of $B$. abortus into professional and nonprofessional phagocytes through suppressing MAPK activation as well as F-actin polymerization. Thus, the medical effects of RBE could be extended to control brucellosis by applying it as a new therapeutic against Brucella infection.

\section{Acknowledgments}

This work was supported by the Strategic Initiative for Microbiomes in Agriculture and Food, Ministry of Agriculture, Food and Rural Affairs, Republic of Korea.

\section{References}

1. Pappas G, Papadimitriou P, Akritidis N, Christou L, Tsianos EV. 2006. The new global map of human brucellosis. Lancet Infect. Dis. 6: $91 \mathrm{e} 9$.

2. Lee JJ, Kim DH, Kim DG, Lee HJ, Min W, Rhee MH, et al. 2012. Phellinus baumii extract influences pathogenesis of Brucella abortus in phagocyte by disrupting the phagocytic and intracellular trafficking pathway. J. Appl. Microbiol. 114: 329-338.

3. Arayan LT, Simborio HL, Reyes AW, Hop HT, Min W, Lee HJ, et al. 2015. The effects of red ginseng saponin fraction-A (RGSF-A) on phagocytosis and intracellular signaling in Brucella abortus infected RAW 264.7 cells. FEMS Microbiol. Lett. 362: fnv070.

4. Pasquevich KA, Estein SM, Garcia-Samartino C, Zwerdling A, 
Coria LM, Barrionuevo P, et al. 2009. Immunization with recombinant Brucella species outer membrane protein Omp16 and Omp19 in adjuvant induces specific CD4+ and CD8+ T cells as well as systemic and oral protection against Brucella abortus infection. Infect. Immun. 77: 436-445.

5. Attele AS, Wu JA, Yuan CS. 1999. Ginseng pharmacology: multiple constituents and multiple actions. Biochem. Pharmacol. 58: 1685-1693.

6. Ng TB, Ling JM, Wang ZT, Cai JN, Xu GJ. 1996. Examination of coumarins, flavonoid and polysaccharopeptide for antibacterial activity. Gen. Pharmacol. 27: 1237-1240.

7. Rehman SU, Chohan ZH, Gulnaz F, Supuran CT. 2005. Invitro antibacterial, antifungal and cytotoxic activities of some coumarins and their metal complexes. J. Enzyme Inhib. Med. Chem. 20: 333-340.

8. Choi SR, Lee JH, Kim JY, Park KW, Jeong IY, Shim KH, et al. 2011. Decursin from Angelica gigas Nakai induces apoptosis in $\mathrm{RC}-58 \mathrm{~T} / \mathrm{h} / \mathrm{SA \# 4}$ primary human prostate cancer cells via a mitochondria-related caspase pathway. Food Chem. Toxicol. 49: 2517-2523.

9. Yim NH, Lee JH, Cho WK, Yang MC, Kwak DH, Ma JY. 2011. Decursin and decursinol angelate from Angelica gigas Nakai induce apoptosis via induction of TRAIL expression on cervical cancer cells. Eur. J. Integr. Med. 3: 299-307.

10. Lee S, Lee YS, Jung SH, Shin KH, Kim BK, Kang SS. 2003. Anti-tumor activities of decursinol angelate and decursin from Angelica gigas. Arch. Pharm. Res. 26: 727-730.

11. Li L, Du JK, Zou LY, Wu T, Lee YW, Kim YH. 2013. Decursin isolated from Angelica gigas Nakai rescues PC12 cells from amyloid beta-protein-induced neurotoxicity through Nrf2-mediated upregulation of heme oxygenase-1: potential roles of MAPK. Evid. Based Complement. Altern. Med. 2013: 467245.

12. Lee KE, Shin JA, Hong IS, Cho NP, Cho SD. 2013. Effect of methanol extracts of Cnidium officinale Makino and Capsella bursa-pastoris on the apoptosis of HSC-2 human oral cancer cells. Exp. Ther. Med. 5: 789-792.

13. Choi NY, Kang SY, Kim KJ. 2015. Artemisia princeps inhibits biofilm formation and virulence-factor expression of antibioticresistant bacteria. Biomed. Res. Int. 2015: 239519.

14. Farooqui A, Khan A, Borghetto I, Kazmi SU, Rubino S, Paglietti B. 2015. Synergistic antimicrobial activity of Camellia sisnensis and Juglans regia against multidrug-resistant bacteria. PLoS One 10: $\mathrm{e} 0118431$.

15. Pham PL, Dupont I, Roy D, Lapointe G, Cernin J. 2000. Production of exopolysaccharide by Lactobacillus rhamnosus $\mathrm{R}$ and analysis of its enzymatic degradation during prolonged fermentation. Appl. Environ. Microbiol. 66: 2302-2310.

16. Lauber K, Bohn E, Kröber SM, Xiao Y. 2003. Apoptotic cells induce migration of phagocytes via caspase-3-mediated release of a lipid attraction signal. Cell 113: 717-730

17. De Bellis P, Valerio F, Sisto A, Lonigro SL, Lavermicocca P. 2010. Probiotic table olives: microbial populations adhering on olive surface in fermentation sets inoculated with the probiotic strain Lactobacillus paracasei IMPC2.1 in an industrial plant. Int. J. Food Microbiol. 140: 6-13.

18. Park JY, Hong M, Jia Q, Lee YC, Yayeh T, Hyun E, et al. 2012. Pistacia chinensis methanolic extract attenuated MAPK and Akt phosphorylations in ADP stimulated rat platelets in vitro. Evid. Based Complement. Alternat. Med. 2012: 895729.

19. Hop HT, Simborio HL, Reyes AW, Arayan LT, Min W, Lee HJ, et al. 2015. Immunogenicity and protective effect of recombinant Brucella abortus Ndk (rNdk) against a virulent strain $B$. abortus 544 infection in BALB/c mice. FEMS Microbiol. Lett. 362: fnv003.

20. Gruenheid S, Finlay BB. 2003. Microbial pathogenesis and cytoskeletal function. Nature 422: 775-781.

21. Lee JJ, Kim DG, Kim DH, Simborio HL, Min W, Lee HJ, et al. 2013. Interplay between clathrin and Rab5 controls the early phagocytic trafficking and intracellular survival of Brucella abortus with HeLa cells. J. Biol. Chem. 288: 28049-28057.

22. Schorey JS, Cooper AM. 2003. Macrophage signaling upon mycobacterial infection: the MAP kinases lead the way. Cell. Microbiol. 5: 133-142.

23. Doyle SE, O'Connell RM, Miranda GA, Vaidya SA, Chow EK, Liu PT, et al. 2004. Toll-like receptors induce a phagocytic gene program through p38. J. Exp. Med. 199: 81-90.

24. Lawhon SD, Maurer R, Suyemoto M, Altier C. 2002. Intestinal short-chain fatty acids alter Salmonella typhimurium invasion gene expression and virulence through BarA/SirA. Mol. Microbiol. 46: 1451-1464.

25. Sun Y, O'Riordan MX. 2013. Regulation of bacterial pathogenesis by intestinal short-chain fatty acids. Adv. Appl. Microbiol. 85: 93-118. 